\title{
Editorial: Medicine man meets machine
}

\author{
Geoff Norman
}

Received: 27 February 2011/ Accepted: 27 February 2011/Published online: 9 March 2011

(C) Springer Science+Business Media B.V. 2011

The academic community is all a'twitter (or is it "all a'Facebook?") over a game show that aired last week. Jeopardy, a long-standing program, had a special show where the two most successful players went head to head with "Watson"-an IBM computer. According to Wikipedia (http://en.wikipedia.org/wiki/Watson):

Watson is a workload optimized system designed for complex analytics, made possible by integrating massively parallel POWER7 processors and the IBM DeepQA software.... Watson is made up of a cluster of ninety IBM Power 750 servers (plus additional I/O, network and cluster controller nodes in 10 racks) with a total of 2880 POWER7 processor cores and 16 Terabytes of RAM. Each Power 750 server uses a $3.5 \mathrm{GHz}$ POWER7 eight core processor.... Watson can process 500 gigabytes, the equivalent of a million books, per second.... [its RAM] contained 200 million pages of structured and unstructured content consuming four terabytes of disk storage,[8] including the full text of Wikipedia.

I have no idea what all that means, but it sounds impressive. Only IBM can afford to make an IBM computer like this one.

For those who avoid TV, Jeopardy is a quiz game where contestants are shown 6 categories, then have to frame a question as an answer, e.g. under North American geography, Q: "The only river that flows into the Arctic", A: What is the Mackenzie River?" Whoever pushes the button first gets to answer. If he's right, he makes money; if he's wrong he loses it.

At the challenge, Watson fairly handily beat the two humans. This was, predictably, billed as a landmark in artificial intelligence computing. But it apparently hinged more on his speed than his accuracy. As Wikipedia says, "Although Watson suffers from cognitive deficiencies when analyzing the clue's contexts, it typically activated its button faster than its opponents."

But that's a bit bothersome. After all, humans have a built in deficit-the $2-300 \mathrm{~ms}$. it takes for the reflex arc to enact a button push. Watson engineers actually had to work on a

G. Norman $(\bowtie)$

MDCL 3519, McMaster University, 1200 Main St. W. Hamilton, ON, Canada

e-mail: norman@mcmaster.ca 
humanoid button-presser, however according to one of the contestants it was still far more precise than he could be. If you add that button-pressing advantage to Watson's overall time, a different winner might have emerged. Moreover, is no one bothered by the fact that Watson can read a million pages of books per second, but still takes 6-7 s to find the right answer? He's clearly digesting more information in a second than any of the other contestants have assimilated in their lifetimes. Whatever he's doing, he's coming in with a huge speed advantage.

There are a few other things that leave me underwhelmed, when it comes to man versus machine. First, the fact is that the machine has to scan zillions of pages of data to find the best match, which makes him little more than a quick and specific Google. We humans, with our jellyfish brains, have to limit the playing field from the outset. So whatever he's doing bears little resemblance to how humans go about it. And Watson's real accomplishment, according to the IBM engineers, is his ability to decode natural language into search commands. That's the opposite of human intelligence. We find it trivial to recognize in a question like "Two of his six wives got the chop" that "chop" refers to beheading, but may have difficulty remembering which number of Henry it is. Watson is the opposite; working out "got the chop" is really hard for him.

Second, when he's right he's dazzling, but when he's wrong he's really wrong. Witness the Final Jeopardy round, where his response to the question in the category "US Cities", "Its largest airport was named for a World War II hero; its second largest, for a World War II battle", was "Toronto". The answer is Chicago (O'Hare and Midway). Now Americans' lack of knowledge of Canadian geography is legendary, but I expect that few Jeopardy contestants would think Toronto was an American city. Watson is like the little girl in the nursery rhyme. When she's good she's very, very good. But when she's bad, she's horrid.

And that is about the only similarity to humans Watson possesses. Showing that a machine, searching a million pages of text a second, can beat a human, in my view is about as revolutionary as showing that a Honda Civic can beat me in a $0-100 \mathrm{~km} / \mathrm{h}$ drag race.

Speaking of human versus machine "intelligence", coincidentally this month's issue of The Atlantic has an article by a journalist, Brian Christian, who entered the competition called the Turing Test. Alan Turing was a British mathematician who committed suicide in 1954 after prosecution and persecution by the British government for homosexuality. (They issued a formal apology in 2009; better late than never). Among other things, he invented the first real computer, called Ultra, that decoded the German Enigma messages and arguably, won the war for the Allies. He also devised the Turing test for artificial intelligence, in which two contestants, man and machine, sit side by side at computers. Judges on the other side of a wall converse with them by keyboard. After 5 min, the judges then deliberate to determine which is the computer and which the human. If the computer fools $30 \%$ of the judges, it has won the Turing Test. No computer has won, although one came close in 2008 (which means, since it's a forced choice, that many humans have been thought to be more like a computer than computers).

The intriguing thing is how one goes about convincing judges you're the human. One might have thought that it was a matter of deep knowledge in a defined narrow area, say British steam locomotives 1862-1872. Not so. The computer can easily stuff all human knowledge of locomotives in its RAM with room left over. Instead the solution is to use the natural language that computers are so bad at to create and follow a very human-like conversation, with instantaneous topic changes, puns, knowledge tailored to the judge's responses. While 2008 was a very close year with computers losing by 1 vote, in 2009 when Christian competed, no computer fooled a judge. Humans had got smarter. 
What does all this have to do with medical education? Two implications. First, the issue of medical computing. In case you need reminding, IBM is in the business of computers. The millions of dollars spent to create Watson was not done to keep the lads busy over lunch. It is intended as a demonstration model of A.I./decision support in the near future. And the first target is medicine. This is stated explicitly in the ad IBM has in the same issue of The Atlantic: "It's how Watson's advances in analytics can be applied to real-world problems: to help doctors make diagnoses rapidly... and help governments provide better services and security".

Let's ignore the last bit from 1984 and stay with medicine. This kind of diagnostic medicine man/machine utopia has been around medicine at least as long as I have. Indeed, my first job involved collecting patient records over a 2 year period in a family practice unit, in part with the amazingly naïve idea that we could use all that data $(250,000$ computer cards as I recall, about $10 \%$ of a $\$ 15$ flash drive) to do diagnosis for the doctor. Others had similar, though much more sophisticated approaches, such as de Dombal's Bayesian programs for abdominal pain (Leaper et al. 1972). But they never made the grade, and after a few decades, we moved to the more modest goal of "decision support systems" to help the doctor, not replace her. Still despite the huge increase in computer power, Internist and QMR still cannot stand alone. They may think of diagnoses that the human missed, but these are lost in a projectile vomit of possibilities. One large national study showed that addition of a decision support system improved physicians' performance by only $2.5 \%$ (Friedman et al. 1999). And to my knowledge no system has been adopted to routine care.

Why so? At least two fundamental reasons. First computers are always dealing with second hand, predigested data. No patient, unless he was a cardiologist, ever announced that he has "retrosternal chest pain of acute onset with radiation down the left arm". And if that is what is checked off on the input list, acute MI is a foregone conclusion. Similarly, no computer can recognize a Babinski sign, a swollen parotid gland, a butterfly rash, or chest rales (although they are getting better at radiologic diagnosis). Second, just as homo sapiens doesn't answer a Jeopardy question by reading a million pages of text, we do not do diagnosis by brute force or mathematical probabilities. Expert clinicians, most of the time, do it by similarity and pattern recognition. And unless computers use neural networks, they don't. As Dreyfus said:

We must be prepared to abandon the traditional view that runs from Plato to Piaget and Chomsky that a beginner starts with specific cases and... abstracts and interiorizes more and more sophisticated rules.It might turn out that skill acquisition moves in just the opposite direction; from abstract rules to particular cases. (Dreyfus 1984)

Perhaps that is not the intent of the IBMers. Maybe they just want to create a much more sophisticated Google for Docs, with instant and intelligent access to all that matters. If so, the performance of Watson does little to set my mind at ease. I fear that, if "Toronto" is anything to go by, a query about "multiple sclerosis, a demyelinating disease" may yield a wealth of information about multiple myeloma and scleroderma.

Now for something more short term and practical. I have known about the Turing test for a long time, and have used an adaptation of it, which I call, with complete absence of creativity, the "Educational Turing Test". It has proven very helpful in focusing the mind about program evaluation.

Suppose you have a new curriculum for first year pharmacy students about ethics and the pharmacist—physician relation. You would like to publish it, to achieve fame and 
glory. But having read our guidelines, you recognize that a bunch of satisfaction measures from students won't cut it. So how can you think about what to evaluate to show the effect of your course?

Might I suggest the Turing Test? Imagine two students at the same level, standing in front of you for their oral exam. They are identical twins, alike in every way but one-John has taken your course but James has not. What questions would you ask of them, short of "Have you taken my course?" to figure out who is who. In short, how would your course be reflected in some kind of knowledge or performance outcome? An outcome of your choosing; not one in the book of objectives.

It's not a bad way to think about the potential benefits (or not) of a course in EBM, health economics, ethics, professionalism, cognitive debiasing, and many others. And it's a great way to decide whether or not to even pursue a program evaluation.

Must go now. The Blackberry is beeping.

\section{References}

Dreyfus, H. L. (1984). The Socratic and Platonic basis of cognitivism. AI and Society, 2, 99-112.

Friedman, C. P., Elstein, A. S., Wolf, F. M., Murphy, G. C., Franz, T. M., Heckerling, P. S., et al. (1999). Enhancement of clinicians' diagnostic reasoning by computer-based consultation: A multisite study of 2 systems. Journal of the American Medical Association, 282, 1851-1856.

Leaper, D. J., Horrocks, J. C., Staniland, J. R., \& De Dombal, F. T. (1972). Computer-assisted diagnosis of abdominal pain using "estimates" provided by clinicians. British Medical Journal, 11, 350-354. 